PAPER

\title{
Prediction of insertion loss of detached houses against road traffic noise using a point sound source model
}

\author{
Kazutoshi Fujimoto*, Kyosuke Tsuji ${ }^{\dagger}$, Toru Tominaga ${ }^{*}$ and Kengo Morita ${ }^{\S}$ \\ Department of Architecture, Faculty of Human-Environment Studies, Kyushu University, \\ Hakozaki 6-10-1, Higashi-ku, Fukuoka, 812-8581 Japan
}

(Received 27 May 2014, Accepted for publication 19 August 2014)

\begin{abstract}
In order to predict equivalent continuous A-weighted sound pressure level $\left(L_{\text {Aeq }}\right)$ of road traffic noise in the area facing roads, a grasp of the insertion loss of buildings against road traffic noise is needed. In the previous study, the authors proposed F2006 for predicting the insertion loss of detached houses against road traffic noise using a line sound source model. However, in order to predict $L_{\mathrm{Aeq}}$ at residential areas facing a curved road, a prediction method based on a point sound source model is needed. Therefore, a new prediction method of the insertion loss of detached houses against road traffic noise is proposed in this paper. The validity of the proposed prediction formula is verified through additional experiments. This simple method is applicable to the evaluation of the Environmental Quality Standards for Noise in Japan.
\end{abstract}

Keywords: Road traffic noise, Insertion loss of buildings, Environmental Quality Standards for Noise

PACS number: 43.50.Rq [doi:10.1250/ast.36.109]

\section{INTRODUCTION}

The Environmental Quality Standards for Noise in Japan (EQS) [1] revised in 1998 describe that the problem of environmental noise at areas facing roads is evaluated by obtaining the numbers and rates of buildings at which noise levels exceed the standard value to the whole buildings. EQS allow for the estimation of noise levels, instead of requiring actual measurements, in cases where taking the actual measurements would be difficult. In order to estimate noise levels, it is necessary to grasp the insertion loss of buildings in an evaluated area. Considering the above information, the authors have proposed an original method of predicting the insertion loss of detached houses against road traffic noise at an area facing a flat road, F2006 [2], and a banked road, F2006 ${ }^{+}$[3]. F2006 and F2006 ${ }^{+}$are adopted in ASJ RTN-Model 2008 [4], which is a standard prediction model of road traffic noise in Japan. However, they are based on a line sound source model and can be applied only to an area along a straight road. On the other hand, ASJ RTN-Model 2008 is, in general, based on a point sound source model, and consequently, it can predict $L_{\text {Aeq }}$ at areas along not only a straight road but also a curved

\footnotetext{
*e-mail: fujimoto@arch.kyushu-u.ac.jp

†e-mail: g2saru@gmail.com

e-mail: tomtoru23@gmail.com

§e-mail: morita@faal.jp
}

road. Therefore, a method of predicting the insertion loss of buildings against road traffic noise using a point sound source model is needed for evaluating EQS at an area along a curved road. In this paper, scale-model experiments are performed, and on the basis of the experimental results, a method of predicting the insertion loss of detached houses against road traffic noise using a point sound source model is proposed. The validity of the proposed formula is verified through additional experiments.

\section{PREDICTION OF INSERTION LOSS AT A POINT WITH A HEIGHT OF $1.2 \mathrm{~m}$}

In this study, two model experiments are performed to examine the method of predicting the insertion loss of detached houses against road traffic noise. Experiment I is aimed at constructing a prediction formula for prediction points with a height of $1.2 \mathrm{~m}$ and Experiment II is for other heights.

\subsection{Experiment I}

\subsubsection{Outline of Experiment I}

Since the procedure of the experiments carried out in this study is almost the same as the previous one for F2006 [2], only an outline is described here. The model scale of the experiment is one-twentieth. Therefore, the dimensions of the experimental model, such as the sizes of the model area and model houses are one-twentieth of the real ones 


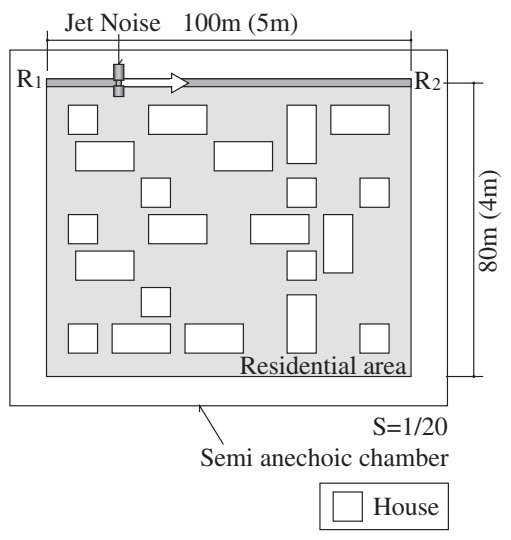

Fig. 1 Outline of the model experiment.

and the model frequency is twenty times the real one. However, only real sizes and frequencies are described hereafter in this paper.

A residential area, $100 \mathrm{~m} \times 80 \mathrm{~m}$, is set in a semianechoic chamber, as shown in Fig. 1, and the sound pressure is measured at a receiving point in the residential area as a model vehicle runs along a straight road $100 \mathrm{~m}$ long. The insertion loss of detached houses against road traffic noise is calculated from the difference between measured sound pressures when there are and are no detached houses present.

2.1.2. Model sound source and receiving points

Jet noise is used as the model sound source. Its frequencies cover a range of $50 \mathrm{~Hz}$ to $4,000 \mathrm{~Hz}$ for road traffic noise, and this noise source is considered to be an omnidirectional point source for those frequencies. The height of the source is $0.3 \mathrm{~m}$ from the ground. The distances between the receiving points and the straight road (d) are $20 \mathrm{~m}, 30 \mathrm{~m}, 40 \mathrm{~m}$, and $50 \mathrm{~m}$; the height from the ground $\left(h_{\mathrm{p}}\right)$ is $1.2 \mathrm{~m}$.

\subsubsection{Model houses}

Each detached house is assumed to be a rectangular parallelepiped, $8 \mathrm{~m} \times 8 \mathrm{~m}$ or $8 \mathrm{~m} \times 16 \mathrm{~m}$ depending on the ground plan, with a height of $10 \mathrm{~m}$, and is to be placed in the residential area at random. The model houses are prepared in four patterns of arrangement, and the ratios of the areas of the houses to the entire residential area, hereafter referred to as the 'covering percentage' $(\omega)$, are $16.8 \%, 21.6 \%, 28.0 \%$, and $34.4 \%$, as shown in Fig. 2. Each $\omega$ and $d$ have four patterns of arrangement, as shown in Table 1. Consequently, the total number of patterns is 64. The model houses are made of polystyrene, which is reflective in the frequency range of the measurements.

\subsubsection{Insertion loss of houses}

The sound pressure is continuously measured while the source is constantly moved from $R_{1}$ to $R_{2}$ in Fig. 1 in $42 \mathrm{~s}$.

The insertion loss of detached houses against road traffic noise is calculated as follows.

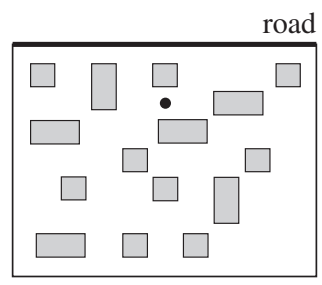

$d=20 \mathrm{~m}, \omega=16.8 \%$

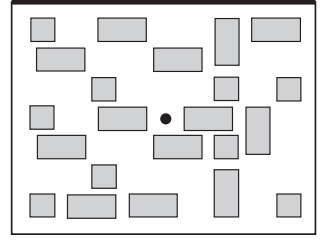

$d=40 \mathrm{~m}, \omega=28.0 \%$
- receiving point

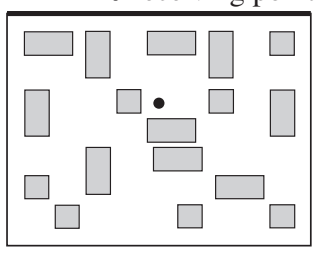

$d=30 \mathrm{~m}, \omega=21.6 \%$

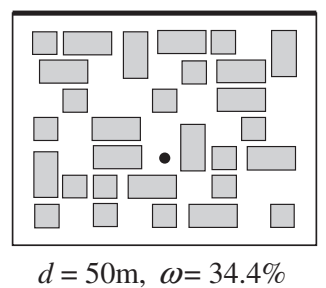

Fig. 2 Examples of arrangement of houses (Exp. I).

Table 1 Experimental conditions (Exp. I).

\begin{tabular}{ccc|cc}
\hline$d$ & $\omega$ & $\begin{array}{c}\text { Number of } \\
\text { arrangements }\end{array}$ & \multicolumn{2}{|c}{ House } \\
\hline $20 \mathrm{~m}$ & $16.8 \%$ & 4 & \multirow{2}{*}{ Plan } & $8 \mathrm{~m} \times 8 \mathrm{~m}$ \\
\cline { 3 - 3 } $30 \mathrm{~m}$ & $21.6 \%$ & 4 & $8 \mathrm{~m} \times 16 \mathrm{~m}$ \\
\cline { 3 - 3 } & $28.0 \%$ & 4 & Height & $H=10 \mathrm{~m}$ \\
\cline { 3 - 3 } $50 \mathrm{~m}$ & $34.4 \%$ & 4 & & \\
\hline
\end{tabular}

First, the analog sound signal measured by a microphone at the receiving point is converted into digital data with $200 \mathrm{kHz}$ as the sampling frequency. Then, each of $16,384\left(=2^{14}\right)$ data values is Fourier-transformed sequentially and power spectrums of each value are calculated. As a result, 512 power spectrums are obtained. Then the $1 / 3$ octave band sound pressure level is calculated from each power spectrum, and frequency characteristics of these $1 / 3$ octave band sound pressure levels are modified by correction values, which are relative values between the spectrum of jet noise and that of road traffic noise in ASJ RTN-Model 2008 (density asphalt, steady-state traffic flow). Thus, A-weighted sound pressure levels $\left(L_{p \mathrm{~A}}\right)$ measured at the receiving point, under the assumption that the model source has the spectrum of road traffic noise, are obtained.

$L_{p \mathrm{~A}}$ values for a vehicle running the central $60 \mathrm{~m}$ zone of the whole road (from $R_{1}$ to $R_{2}$ ) are selected from among all data, and the energy average of $L_{p \mathrm{~A}}\left(L_{\mathrm{B}}\right)$ for a running vehicle is calculated for every $10 \mathrm{~m}$ of road. The difference between $L_{\mathrm{B}, 1}$, which is $L_{\mathrm{B}}$ in the presence of houses, and $L_{\mathrm{B}, 0}$, which is $L_{\mathrm{B}}$ without houses, $\left(\Delta L_{\mathrm{B}}=L_{\mathrm{B}, 1}-L_{\mathrm{B}, 0}\right)$ is calculated. Thus, 7,744 values of $\Delta L_{\mathrm{B}}$ are obtained in the whole experiment (121 values for each arrangement $\times 64$ arrangements). $\Delta L_{\mathrm{B}}$ is the insertion loss of detached houses against road traffic. However, it should be noted that $\Delta L_{\mathrm{B}}$ has a sign contrary to that in the usual definition. 


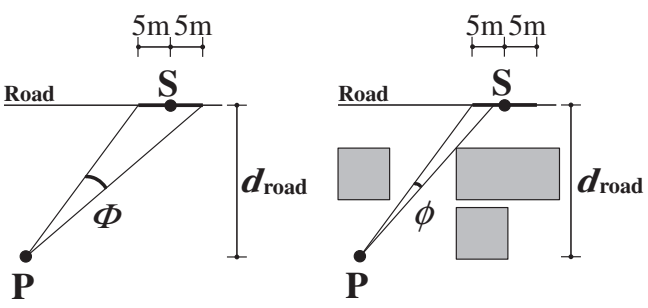

Fig. $3 \Phi$ and $\phi$.

It is well known that air absorption is not negligible when considering the propagation of high-frequency sound. Nevertheless, it is omitted from calculating $\Delta L_{\mathrm{B}}$ because the difference between the sound absorption of $L_{\mathrm{B}, 1}$ and that of $L_{\mathrm{B}, 0}$ is thought to be very small.

\subsection{Construction of Prediction Formula}

Since this study is aimed at constructing a simple method of predicting the insertion loss of detached houses against road traffic noise, the following model is assumed for predicting $\Delta L_{\mathrm{B}}$.

$$
\Delta L_{\mathrm{B}}=10 \log _{10} \frac{E_{\mathrm{dir}}+E_{\mathrm{ref}}+E_{\mathrm{dif}}}{E_{0}}
$$

Here, $E_{\mathrm{dir}}, E_{\mathrm{ref}}$, and $E_{\mathrm{dif}}$ are sound energies of direct sound, reflection, and diffraction, respectively, and $E_{0}$ is sound energy when there are no houses.

\subsubsection{Direct sound}

First, $E_{\mathrm{dir}}$, the energy of direct sound, is examined. Let us consider a road of $10 \mathrm{~m}$ length where the sound source $S$ is the midpoint, as shown in Fig. 3. Here, $\Phi$ is an angle [rad] determined by the road that is visible from prediction point $P$. In the same manner, when there are houses, the angle [rad] determined by the road visible from prediction point $\mathrm{P}$ becomes $\phi$. According to the theoretical formula of sound propagation in a free sound field for a finite line source, $E_{\mathrm{dir}}$ is

$$
\begin{aligned}
10 \log _{10} \frac{E_{\text {dir }}}{E_{0}} & =10 \log _{10} \frac{\phi}{d_{\text {road }}}-10 \log _{10} \frac{\Phi}{d_{\text {road }}} \\
& =10 \log _{10} \frac{\phi}{\Phi} .
\end{aligned}
$$

Here, $d_{\text {road }}$ is the perpendicular distance of the prediction point from the road.

The relationship between $\Delta L_{\mathrm{B}}$ and $\phi / \Phi$ is shown in Fig. 4. A correlation is recognized between them. However, differences of about $10 \mathrm{~dB}$ are seen when $\phi / \Phi$ is not zero (the road is partially visible from the prediction point) and greater differences are seen when $\phi / \Phi$ is zero (the road is not visible from the prediction point at all). This shows that reflections and diffractions must be considered to enable better prediction of $\Delta L_{\mathrm{B}}$.

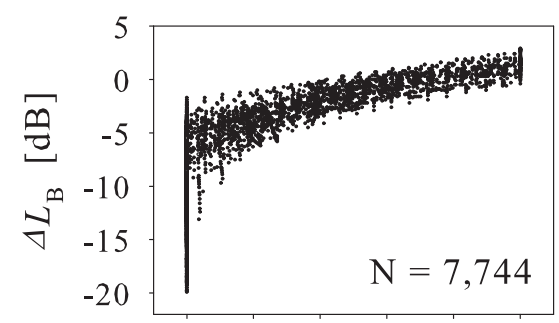

$\begin{array}{llllll}0.0 & 0.2 & 0.4 & 0.6 & 0.8 & 1.0\end{array}$

$\phi / \Phi[-]$

Fig. 4 Relationship between $\Delta L_{\mathrm{B}}$ and $\phi / \Phi$.

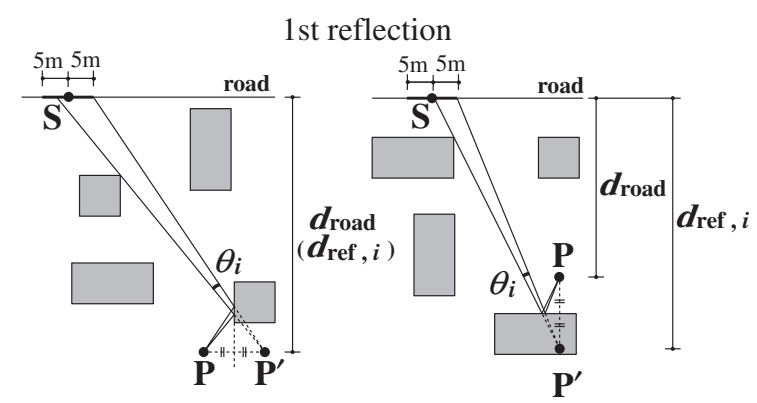

2nd reflection

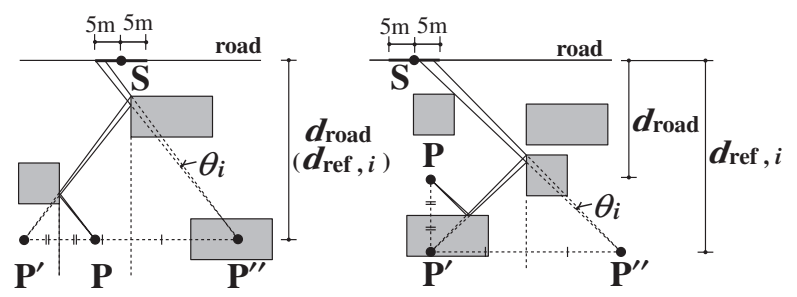

Fig. $5 \theta_{i}$ and $d_{\mathrm{ref}, i}$.

\subsubsection{Reflections}

Next, $E_{\text {ref }}$, the energy of reflection by houses, is examined. When a simple model, in which sound is assumed to propagate like a ray in accordance with geometrical acoustics, and only the first and second reflections by houses are considered, as shown in Fig. 5, $E_{\text {ref }}$ is expressed by

$$
\begin{aligned}
10 \log _{10} \frac{E_{\text {ref }}}{E_{0}} & =10 \log _{10} \sum_{i} \frac{\theta_{i}}{d_{\text {ref }, i}}-10 \log _{10} \frac{\Phi}{d_{\text {road }}} \\
& =10 \log _{10} \sum_{i}\left(\frac{\theta_{i}}{\Phi} \cdot \frac{d_{\text {road }}}{d_{\text {ref }, i}}\right) .
\end{aligned}
$$

Here, $\theta_{i}$ is an angle [rad] determined by the road that is visible from mirror point $\mathrm{P}^{\prime}$ and $\mathrm{P}^{\prime \prime}$ of prediction point $\mathrm{P}$ against the reflecting wall of houses and $d_{\text {ref }, i}$ is the perpendicular distance of $\mathrm{P}^{\prime}$ and $\mathrm{P}^{\prime \prime}$ from the road. $\sum_{i}$ means the summation of the first and second reflections, while the third and more reflections are ignored.

\subsubsection{Diffractions}

Sounds other than direct sound and reflections propagating through the gaps between houses or passing over the houses also arrive at $\mathrm{P}$. The largest component might be 


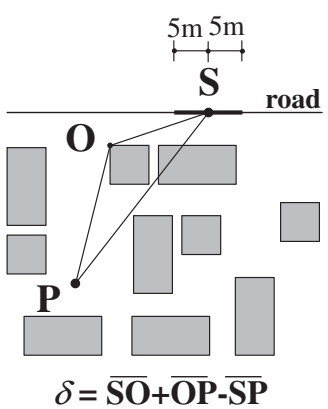

Fig. 6 First diffraction.

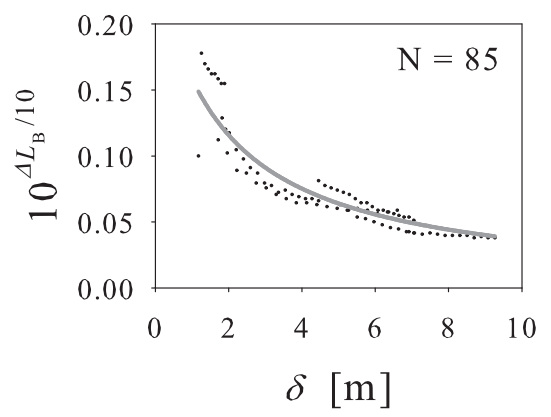

Fig. 7 Relationship between $\Delta L_{\mathrm{B}}$ and $\delta$.

sound that diffracts only once at point $\mathrm{O}$ and arrives at $\mathrm{P}$, as shown in Fig. 6. Here, this component is defined as the first diffraction energy, $E_{\mathrm{dif}, 1}$. As $E_{\mathrm{dif}, 1}$ might depend on the diffraction pass difference, $\delta(=\overline{\mathrm{SO}}+\overline{\mathrm{OP}}-\overline{\mathrm{SP}})$, the relationship between $\Delta L_{\mathrm{B}}$ and $\delta$ is shown in Fig. 7, where only 85 values of $\Delta L_{\mathrm{B}}$, which have no components of $E_{\mathrm{dir}}$ and $E_{\text {ref }}$ among 7,744 values, are plotted. As a result of correlation analysis based on a least-squares method, $10^{\Delta L_{\mathrm{B}}}=0.251 /(1+0.522 \delta)$ is obtained. As $E_{\mathrm{dif}, 1}$ is sound energy from a finite line source in the same manner as for direct sound or reflection (refer to Sects. 2.2.1 and 2.2.2), $E_{\mathrm{dif}, 1}$ is expressed as below by averaging the energies of all diffractions at a diffraction point after being emitted from each discrete point sound source in a finite line source

$$
E_{\mathrm{dif}, 1}=\frac{1}{n} \sum_{k=1}^{n}\left(\frac{0.251}{1+0.522 \delta_{k}}\right) .
$$

Here, $n$ is the number of point sound sources set on the road of $10 \mathrm{~m}$ length, as shown in Fig. $6 . k$ shows each point sound source. However, point sound sources that are visible from the prediction point are omitted from this summation.

Now, sounds other than single diffraction, defined as $E_{\mathrm{dif}, 2}$, are examined. As it is very difficult to find out parameters based on the diffraction path differences for $E_{\mathrm{dif}, 2}, d_{\mathrm{SP}}$ and $\xi$ are employed as parameters for $E_{\mathrm{dif}, 2}$. Here, $d_{\mathrm{SP}}$ is the horizontal distance of prediction point $\mathrm{P}$ from

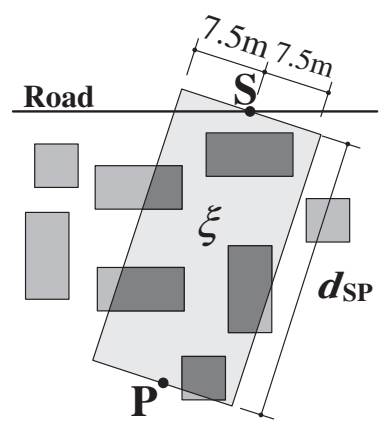

Fig. $8 d_{\mathrm{SP}}$ and $\xi$.

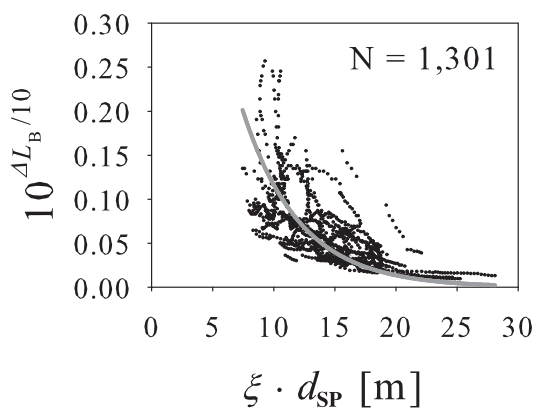

Fig. 9 Relationship between $\Delta L_{\mathrm{B}}$ and $\xi \cdot d_{\mathrm{SP}}$.

sound source point $\mathrm{S}$ and $\xi$ is the house density in a rectangular area with a width of $15 \mathrm{~m}$ and a length of $d_{\mathrm{SP}}$, as shown in Fig. 8. Figure 9 shows the relationship between $\Delta L_{\mathrm{B}}$ and $\xi \cdot d_{\mathrm{SP}}$, where only 1,301 values of $\Delta L_{\mathrm{B}}$, which have no energy of direct sound, reflection, or the first diffractions, among the 7,744 values are plotted. As a result of the correlation analysis based on a least-squares method, the following equation is obtained.

$$
E_{\mathrm{dif}, 2}=10^{-0.0904 \xi \cdot d_{\mathrm{SP}}}
$$

Thus, $E_{\text {dif }}$ is expressed as

$$
\begin{aligned}
E_{\mathrm{dif}} & =E_{\mathrm{dif}, 1}+E_{\mathrm{dif}, 2} \\
& =\frac{1}{n} \sum_{k=1}^{n}\left(\frac{0.251}{1+0.522 \delta_{k}}\right)+10^{-0.0904 \xi \cdot d_{\mathrm{SP}} .}
\end{aligned}
$$

\subsubsection{Prediction formula of $\Delta L_{\mathrm{B}}$}

From the results, a prediction formula of $\Delta L_{\mathrm{B}}$ is obtained by substituting Eqs. (2), (3), and (4) into Eq. (1). As the contribution of each component has not yet been elucidated, a least-squares method is adopted and correlation coefficients for each component are calculated. Then the least-squares method is applied again to the experimental data and those calculated using the equation, and constant $a_{0}$ in Eq. (5) is determined. Thus, the prediction formula of $\Delta L_{\mathrm{B}}$ is given by Eq. (5) and is called F2012a hereafter. Since this prediction formula is effective only when $H$ is $10 \mathrm{~m}$ and $h_{\mathrm{p}}$ is $1.2 \mathrm{~m}$, the notation of $\Delta L_{\mathrm{B}}$ is modified to $\Delta L_{\mathrm{B}, H=10, h_{\mathrm{p}}=1.2}$ for definiteness. 

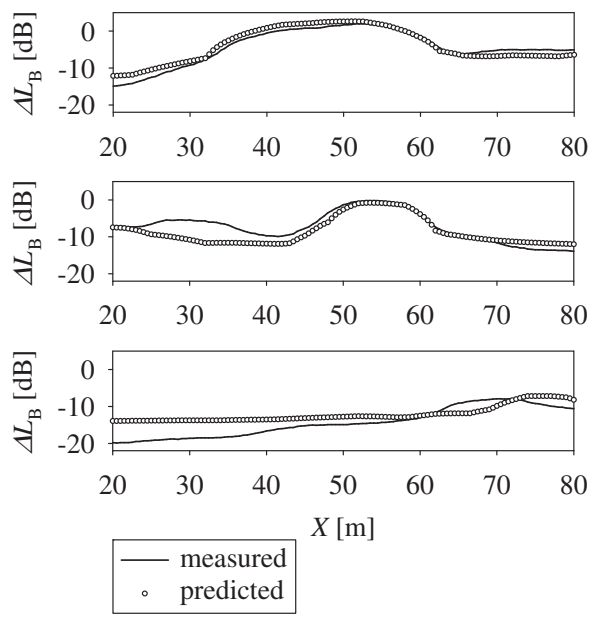

Fig. 10 Comparison of experimental unit patterns with predicted ones (Exp. I).

$$
\begin{aligned}
\Delta L_{\mathrm{B}, H=10, h_{\mathrm{p}}=1.2}= & 10 \log _{10}\left\{a_{0}+a_{1} \cdot \frac{\phi}{\Phi}\right. \\
& +a_{2} \sum_{i}\left(\frac{\theta_{i}}{\Phi} \cdot \frac{d_{\mathrm{road}}}{d_{\mathrm{ref}, i}}\right) \\
& +a_{3} \cdot \frac{1}{n} \sum_{k=1}^{n}\left(\frac{0.251}{1+0.522 \delta_{k}}\right) \\
& \left.+a_{4} \cdot 10^{-0.0904 \xi \cdot d_{\mathrm{SP}}}\right\}
\end{aligned}
$$

$\phi$ : Perspective angle to a road from a prediction point when there are house, [rad]

$\Phi$ : Perspective angle to a road from a prediction point when there are no houses, [rad]

$\theta_{i}$ : Perspective angle to a road from an image prediction point, [rad]

$d_{\text {road }}$ : Perpendicular distance from a prediction point to a road, [m]

$d_{\text {ref }, i}$ : Perpendicular distance from an image prediction point to a road, [m]

$\delta_{k}$ : Diffraction path difference of the first diffraction, [m]

$\xi:$ House density in a rectangle, [-]

$d_{\mathrm{SP}}$ : Horizontal distance from a sound source point $(\mathrm{S})$ to a prediction point $(\mathrm{P}),[\mathrm{m}]$

Here, $a_{0}=0.0390, a_{1}=1.16, a_{2}=0.201, a_{3}=0.346$, and $a_{4}=0.288$. Because of the experimental conditions, F2012a is valid only when $d_{\text {road }}$ is within $50 \mathrm{~m}$, the height of the prediction point is $1.2 \mathrm{~m}$ above the ground, and the $\omega$ is between $16.8 \%$ and $34.4 \%$.

\subsubsection{Precision of F2012a}

Three examples of comparisons between experimental unit patterns and those predicted using Eq. (5) among 64 arrangements are shown in Fig. 10. Fairly good agreement between experimental values ('black line') and predicted ones ('circle') is found in the uppermost figure, while slight

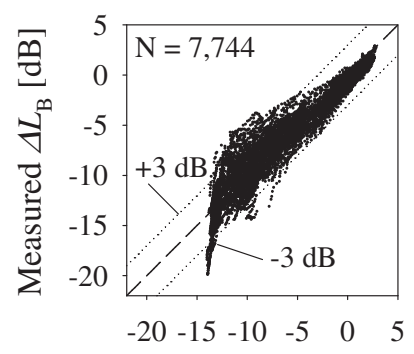

Predicted $\Delta L_{\mathrm{B}}[\mathrm{dB}]$

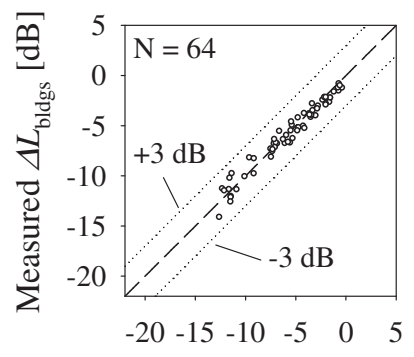

Predicted $\Delta L_{\text {bldgs }}[\mathrm{dB}]$
Fig. 11 Comparison of experimental $\Delta L_{\mathrm{B}}$ (left) and $\Delta L_{\text {bldgs }}$ (right) with predicted ones (Exp. I).

Table 2 Experimental conditions (Exp. Ia and Ib).

\begin{tabular}{ccc|cc}
\hline$d$ & $\omega$ & $\begin{array}{c}\text { Number of } \\
\text { arrangements }\end{array}$ & \multicolumn{2}{|c}{ House } \\
\hline $20 \mathrm{~m}$ & $16.8 \%$ & 1 & \multirow{2}{*}{ Plan } & $8 \mathrm{~m} \times 8 \mathrm{~m}$ \\
$30 \mathrm{~m}$ & $21.6 \%$ & 1 & & $8 \mathrm{~m} \times 16 \mathrm{~m}$ \\
$40 \mathrm{~m}$ & $28.0 \%$ & 1 & Height & $H=10 \mathrm{~m}$ \\
\cline { 3 - 3 } $50 \mathrm{~m}$ & $34.4 \%$ & 1 & & \\
\hline
\end{tabular}

differences are found in the lower two figures when the value of $\Delta L_{\mathrm{B}}$ is small, however, over all, predicted values are greater than experimental ones (this means that F2012a provides safer prediction from the viewpoint of noise prediction when the value of $\Delta L_{\mathrm{B}}$ is small).

All experimental $\Delta L_{\mathrm{B}}$ values and those predicted using Eq. (5) are compared in Fig. 11 (left). The root mean square (RMS) of differences between experimental and predicted values and the maximum difference are $1.6 \mathrm{~dB}$ and $6.0 \mathrm{~dB}$, respectively, and $92 \%$ of predicted data are within $\pm 3 \mathrm{~dB}$ of experimental data. Figure 11 (right) shows the comparison between experimental and calculated $\Delta L_{\text {bldgs }}$ values for 64 arrangements of houses, where $\Delta L_{\text {bldgs }}$ is the averaged energy level of $\Delta L_{\mathrm{B}}$ for a vehicle running from $R_{1}$ to $R_{2}$ in Fig. 1. RMS and the maximum difference are $0.7 \mathrm{~dB}$ and $1.7 \mathrm{~dB}$, respectively. This shows that F2012a has good accuracy.

\subsection{Validity of F2012a}

In order to verify the validity of F2012a, two types of additional model experiments (Experiment Ia: straight road, Experiment Ib: curved road) are performed.

2.3.1. Experiment Ia (straight road)

The procedure of Experiment Ia is almost the same as that of Experiment I descrived in Sect. 2.1. The experimental conditions are shown in Table 2. The $\omega$ values are $16.8 \%, 21.6 \%, 28.0 \%$, and $34.4 \%$, and the $d$ values are $20 \mathrm{~m}, 30 \mathrm{~m}, 40 \mathrm{~m}$, and $50 \mathrm{~m}$. By combining them, the number of arrangements of houses is 16 , where 


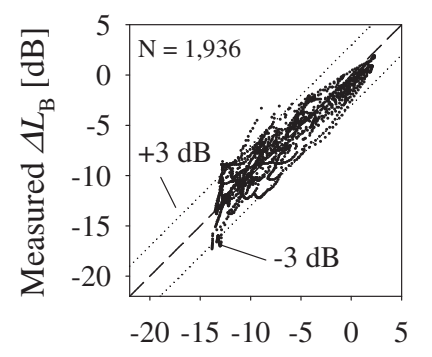

Predicted $\Delta L_{\mathrm{B}}[\mathrm{dB}]$

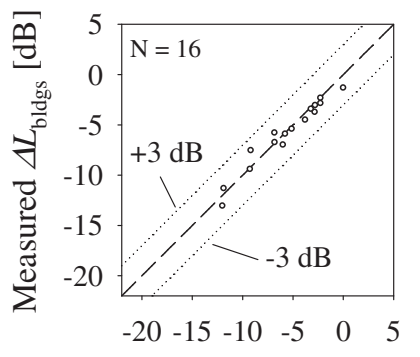

Predicted $\Delta L_{\text {bldgs }}[\mathrm{dB}]$
Fig. 12 Comparison of experimental $\Delta L_{\mathrm{B}}$ (left) and $\Delta L_{\text {bldgs }}$ (right) with predicted ones (Exp. Ia).

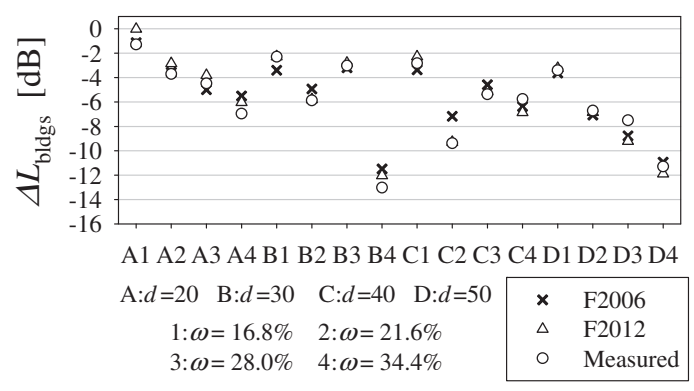

Fig. 13 Comparison of F2012 and F2006.

each arrangement of houses is different from that in Experiment I. Consequently, 1,936 values of $\Delta L_{\mathrm{B}}$ are obtained.

A comparison between experimental $\Delta L_{\mathrm{B}}$ values and those predicted using Eq. (5) is shown in Fig. 12 (left). RMS and the maximum difference are $1.5 \mathrm{~dB}$ and $5.8 \mathrm{~dB}$, respectively, and $94 \%$ of predicted data are within $\pm 3 \mathrm{~dB}$ of experimental data. Figure 12 (right) shows the comparison between experimental and calculated $\Delta L_{\text {bldgs }}$ values for 16 arrangements. RMS and the maximum difference are $0.8 \mathrm{~dB}$ and $1.8 \mathrm{~dB}$, respectively. These results confirm that F2012a has good accuracy for a straight road.

For a straight road, $\Delta L_{\text {bldgs }}$ can also be predicted by F2006 [2], which is based on a line sound source model. 16 data values for arrangements of houses are plotted in Fig. 13, where $\Delta L_{\text {bldgs }}$ values predicted by F2012 ('triangles') and those predicted by F2006 ('crosses') are compared with the experimental values ('circles'). Althougt the values predicted by F2012 are, on the whole, slightly smaller than those predicted by F2006, the difference is very small. RMS values between experimental and predicted values are $1.0 \mathrm{~dB}$ for $\mathrm{F} 2006$ and $0.8 \mathrm{~dB}$ for F2012. This shows that F2012 has higher accuracy than F2006 for a straight road.

\subsubsection{Experiment Ib (curved road)}

The experimental conditions in Experiment $\mathrm{Ib}$ are shown in Table 2. The road is an arc of a circle with a radius of $100 \mathrm{~m}$. The $\omega$ values are $16.6 \%, 21.5 \%, 28.3 \%$,

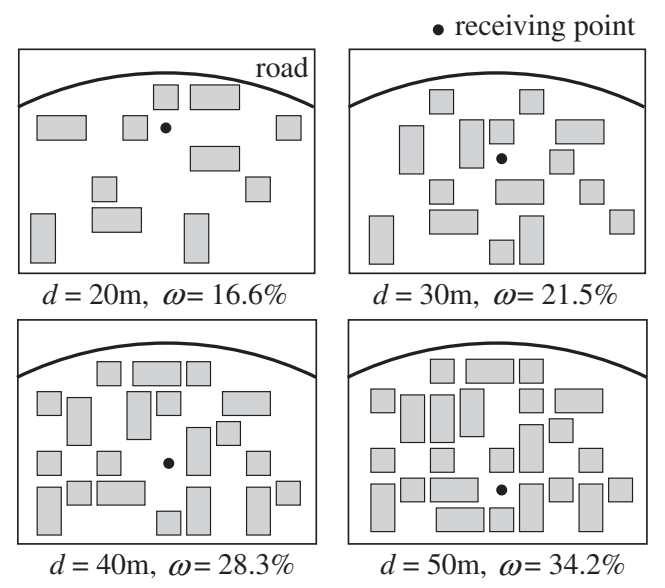

Fig. 14 Examples of arrangement of houses (Exp. Ib).
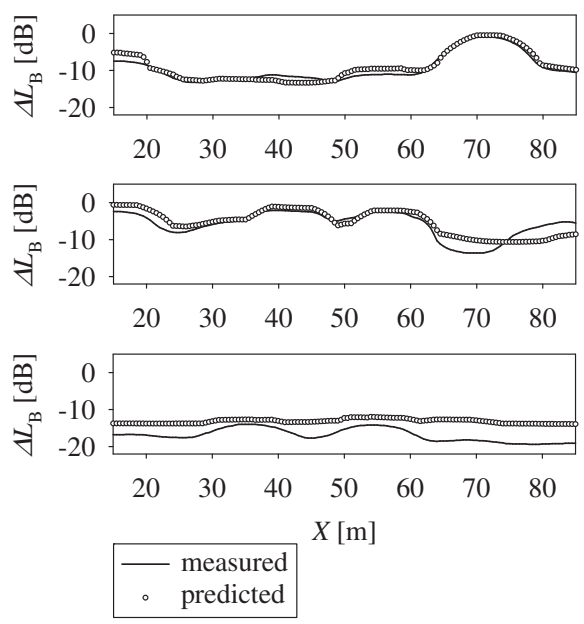

Fig. 15 Comparison of experimental unit patterns with predicted ones (Exp. Ib).

and $34.2 \%$, and other conditions are almost the same as those in Experiment I. The number of arrangements of houses is 16 (4 examples are shown in Fig. 14), and 2,256 values of $\Delta L_{\mathrm{B}}$ are obtained.

Figure 15 shows 3 examples of unit patterns from among the 16 arrangements. A similar relationship between the experimental ('black line') and predicted ('circles') values to that in Fig. 10 is seen.

A comparison between the experimental and the predicted $\Delta L_{\mathrm{B}}$ values is shown in Fig. 16 (left). RMS and the maximum difference are $1.9 \mathrm{~dB}$ and $5.8 \mathrm{~dB}$, respectively, and $89 \%$ of predicted data are within $\pm 3 \mathrm{~dB}$ of experimental data. Figure 16 (right) shows the comparison between experimental and calculated $\Delta L_{\text {bldgs }}$ values for the 16 arrangements. RMS and the maximum difference are $1.2 \mathrm{~dB}$ and $3.4 \mathrm{~dB}$, respectively. These results confirm that F2012a has good accuracy for a curved road as well.

The method of calculating the parameters in Eq. (5) for a curved road has been introduced in Ref. 5 . 


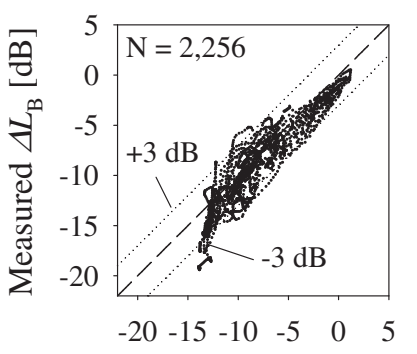

Predicted $\Delta L_{\mathrm{B}}[\mathrm{dB}]$

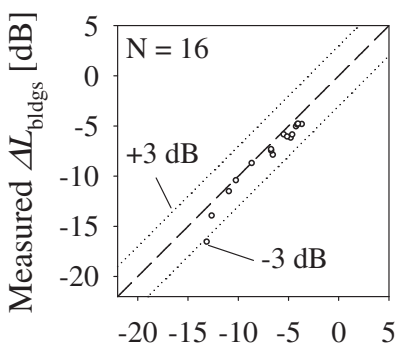

Predicted $\Delta L_{\text {bldgs }}[\mathrm{dB}]$

Fig. 16 Comparison of experimental $\Delta L_{\mathrm{B}}$ (left) and $\Delta L_{\text {bldgs }}$ (right) with predicted ones (Exp. Ib).

Table 3 Experimental conditions (Exp. II).

\begin{tabular}{|c|c|c|c|c|}
\hline$d$ & $\omega$ & $\begin{array}{c}\text { Number of } \\
\text { arrangements }\end{array}$ & & House \\
\hline $20 \mathrm{~m}$ & $16.8 \%$ & 1 & \multirow{2}{*}{ Plan } & \multirow{4}{*}{$\begin{array}{l}8 \mathrm{~m} \times 8 \mathrm{~m} \\
8 \mathrm{~m} \times 16 \mathrm{~m} \\
H=10,7,4 \mathrm{~m}\end{array}$} \\
\hline $30 \mathrm{~m}$ & $21.6 \%$ & 1 & & \\
\hline $40 \mathrm{~m}$ & $28.0 \%$ & 1 & \multirow{2}{*}{ Height } & \\
\hline $50 \mathrm{~m}$ & $34.4 \%$ & 1 & & \\
\hline
\end{tabular}

\section{PREDICTION FORMULA TAKING THE HEIGHTS OF BUILDINGS AND PREDICTION POINT INTO CONSIDERATION}

F2012a confines the heights of buildings and the prediction point to $10 \mathrm{~m}$ and $1.2 \mathrm{~m}$ above the ground, respectively. However, there are many detached houses with heights smaller than $10 \mathrm{~m}$. Consequently, $L_{\text {Aeq }}$ must be predicted at points with heights other than $1.2 \mathrm{~m}$ to evaluate EQS. Therefore, in this section, we examine the expansion of F2012a to make it applicable when the height of buildings is less than $10 \mathrm{~m}$ and the height of the prediction point is smaller than that of the buildings. For this purpose, Experiment II is performed.

\subsection{Experiment II}

Since the outline of Experiment II is almost the same as that of Experiment I, except the heights of detached houses and receiving points, the detailed description is omitted here. The experimental conditions of Experiment II are shown in Table 3. The $\omega$ values are $16.8 \%, 21.6 \%, 28.0 \%$, and $34.4 \%$, and the $d$ values are $20 \mathrm{~m}, 30 \mathrm{~m}, 40 \mathrm{~m}$, and $50 \mathrm{~m}$. By combining them, the number of arrangements of houses is 16 . The $H$ values are $10 \mathrm{~m}, 7 \mathrm{~m}$, and $4 \mathrm{~m}$, which are constant in each arrangement of houses. The $h_{\mathrm{p}}$ values are $1.2 \mathrm{~m}, 2.2 \mathrm{~m}, 3.2 \mathrm{~m}, 5.2 \mathrm{~m}, 6.2 \mathrm{~m}, 8.2 \mathrm{~m}$, and $9.2 \mathrm{~m}$ when $H$ is $10 \mathrm{~m} ; 1.2 \mathrm{~m}, 2.2 \mathrm{~m}, 3.2 \mathrm{~m}$, and $5.2 \mathrm{~m}$ when $H$ is $7 \mathrm{~m}$; and $1.2 \mathrm{~m}, 2.2 \mathrm{~m}$, and $3.2 \mathrm{~m}$ when $H$ is $4 \mathrm{~m}$. Thus, the number of combinations of $H$ and $h_{\mathrm{p}}$ is 14 . The experimental results are analyzed in the same manner as
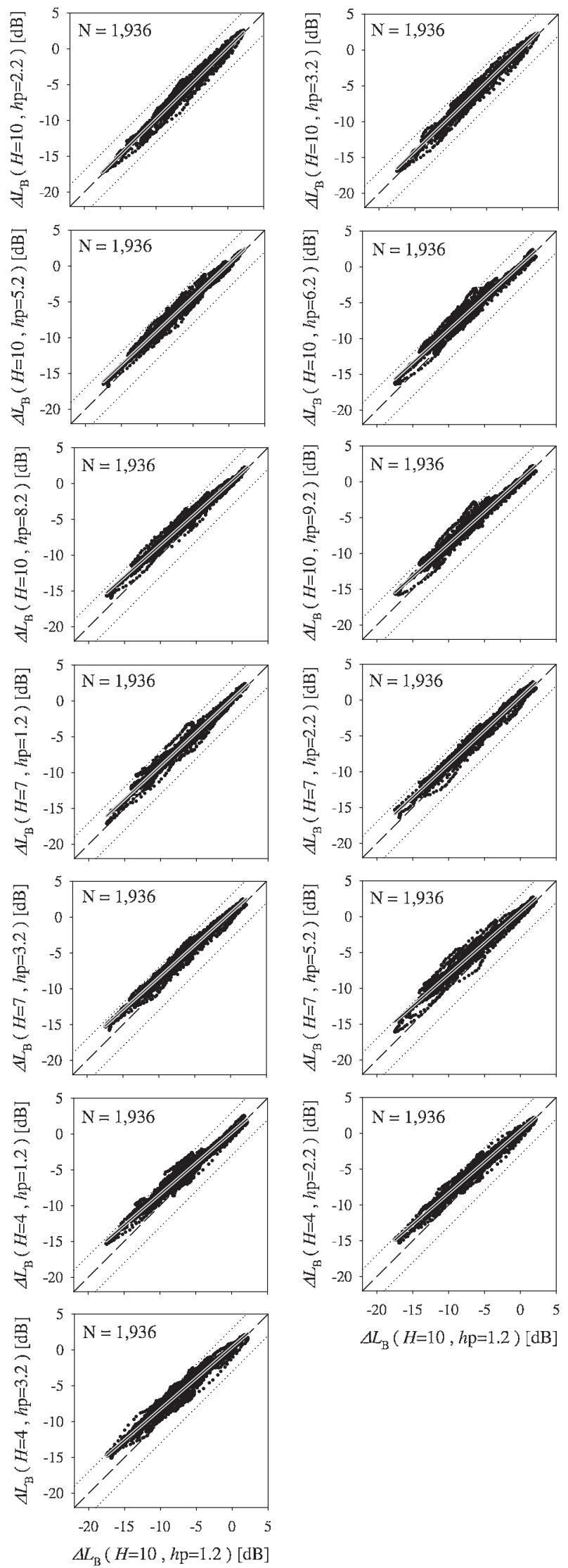

Fig. 17 Comparison of $\Delta L_{\mathrm{B}}$ with $\Delta L_{\mathrm{B}, H=1.2, h_{\mathrm{p}}=1.2}$.

described in Sect. 2.1.4, and 1,936 values of $\Delta L_{\mathrm{B}}$ are obtained for each combination of $H$ and $h_{\mathrm{p}}$ (14 patterns). 


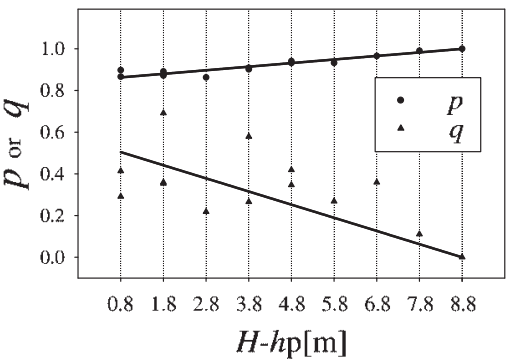

Fig. 18 Relationships between $p, q$, and $\left(H-h_{\mathrm{p}}\right)$.

\subsection{Construction of Prediction Formula}

All values of $\Delta L_{\mathrm{B}}$ for each $H$ and $h_{\mathrm{p}}$ are compared with $\Delta L_{\mathrm{B}}$ when $H=10$ and $h_{\mathrm{p}}=1.2$ in Fig. 17. It is found that $\Delta L_{\mathrm{B}}$ increases as the height of houses $(H)$ decreases and the height of the prediction point $\left(h_{\mathrm{p}}\right)$ increases. Since this could be caused by the sound energy propagating over the houses, the difference between $H$ and $h_{\mathrm{p}},\left(H-h_{\mathrm{p}}\right)$ is examined to grasp the difference between $\Delta L_{\mathrm{B}}$ for each $H$ and $h_{\mathrm{p}}$ from $\Delta L_{\mathrm{B}}$ when $H=10$ and $h_{\mathrm{p}}=1.2$. As all relationships in Fig. 17 are linear, a regression analysis is applied. As a result, the gradient $p$ and intercept $q$ of the linear regression line are obtained. The relationships between $p, q$, and $\left(H-h_{\mathrm{p}}\right)$ are shown in Fig. 18. As linear relationships are found for both $p$ and $q$ with $\left(H-h_{\mathrm{p}}\right)$, a regression analysis is again applied.

Thus, a prediction formula for $\Delta L_{\mathrm{B}}$ that takes the heights of houses and the prediction point into consideration is obtained as Eq. (6). Equations (5) and (6) together are called F2012 hereafter.

$$
\begin{aligned}
\Delta L_{\mathrm{B}} & =p \cdot \Delta L_{\mathrm{B}, H=10, h_{\mathrm{p}}=1.2}+q \\
p & =0.017\left(H-h_{\mathrm{p}}-8.8\right)+1.0 \\
q & =-0.063\left(H-h_{\mathrm{p}}-8.8\right)
\end{aligned}
$$

\subsection{Precision of Eq. (6)}

All experimental values of $\Delta L_{\mathrm{B}}$ are compared with those calculated using Eq. (6) [6]; however, they are not shown in this paper on account of limited space. RMS of differences and the maximum difference are $1.9 \mathrm{~dB}$ and $6.4 \mathrm{~dB}$, respectively. They are nearly equal to the values for $\mathrm{F} 2012 \mathrm{a}(1.6 \mathrm{~dB}$ and $6.0 \mathrm{~dB}$, respectively). Then, 14 values of $\Delta L_{\text {bldgs }}$ are compared with those calculated using Eq. (6). RMS of differences and the maximum difference are $0.8 \mathrm{~dB}$ and $1.9 \mathrm{~dB}$, respectively, and they are nearly equal to the values for $\mathrm{F} 2012 \mathrm{a}(0.7 \mathrm{~dB}$ and $1.7 \mathrm{~dB}$, respectively). The above results show that Eq. (6) has almost the same accuracy as F2012a.

\subsection{Comparison of F2012 with F2006}

When a road is straight, $\Delta L_{\text {bldgs }}$ can also be predicted by F2006 [2] using a line sound source model. To compare the accuracies of F2012 and F2006 for a straight road,
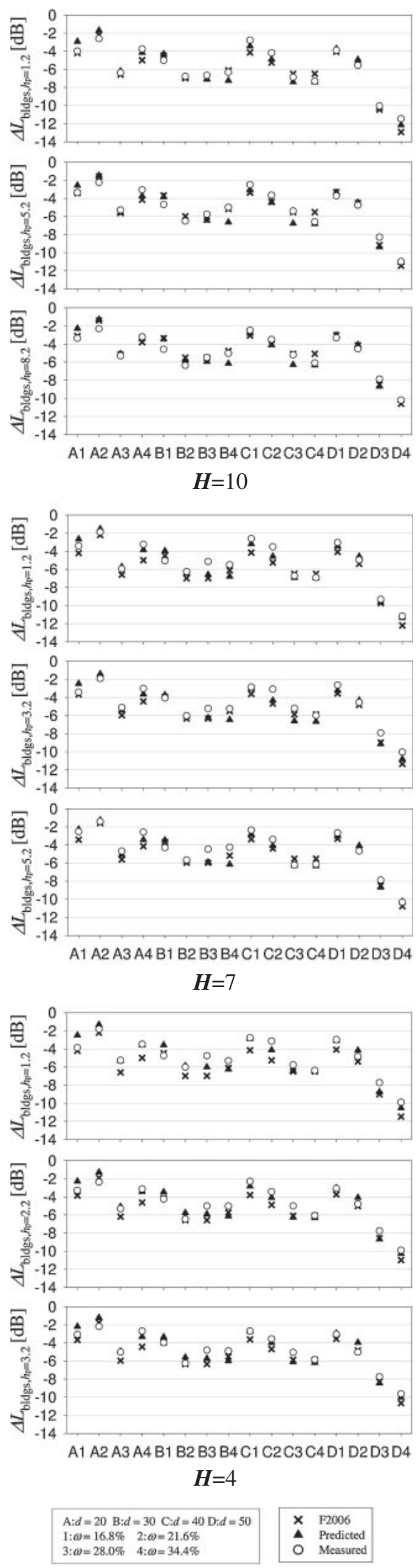

Fig. 19 Comparison of F2012 and F2006 (Exp. II).

the experimental $\Delta L_{\text {bldgs }}$ values ('circles') are compared with those predicted by F2012 ('triangles') and F2006 ('crosses') in Fig. 19, in which only 9 among the 14 
patterns are shown. The results show that $52 \%$ of $\Delta L_{\text {bldgs }}$ values predicted by F2012 have better agreement with the experimental ones than those predicted by F2006. RMS and the maximum difference between the experimental and predicted values are $0.6 \mathrm{~dB}$ and $0.8 \mathrm{~dB}$, and they are $0.7 \mathrm{~dB}$ and $1.2 \mathrm{~dB}$ for F2006, respectively. This shows that F2012 has a heigher accuracy than F2006 for a straight road.

\subsection{Examination of Validity of F2012}

To verify that F2012 is effective for a curved road, an additional model experiment (Experiment IIa) is performed. The experimental conditions of Experiment IIa are shown in Table 4. The road is an arc of a circle with a radius of $100 \mathrm{~m}$. The $d$ values are $20 \mathrm{~m}, 30 \mathrm{~m}, 40 \mathrm{~m}$, and $50 \mathrm{~m}$, and the $\omega$ values are $16.6 \%$ and $21.5 \%$ for $d$ values of $20 \mathrm{~m}$ and $40 \mathrm{~m}$, and $28.3 \%$ and $34.2 \%$ for $d$ values of $30 \mathrm{~m}$ and $50 \mathrm{~m}$. Thus, the number of arrangements of houses is 8 . The $H$ values are $10 \mathrm{~m}, 7 \mathrm{~m}$, and $4 \mathrm{~m}$, where $H$ is constant
Table 4 Experimental conditions (Exp. IIa).

\begin{tabular}{|c|c|c|c|c|}
\hline$d$ & $\omega$ & $\begin{array}{l}\text { Number of } \\
\text { arrangements }\end{array}$ & & House \\
\hline $20 \mathrm{~m}$ & $16.6 \%$ & 1 & \multirow{4}{*}{ Height } & \multirow{4}{*}{$\begin{array}{l}8 \mathrm{~m} \times 8 \mathrm{~m} \\
8 \mathrm{~m} \times 16 \mathrm{~m} \\
H=10,7,4 \mathrm{~m}\end{array}$} \\
\hline $40 \mathrm{~m}$ & $21.5 \%$ & 1 & & \\
\hline $30 \mathrm{~m}$ & $28.3 \%$ & 1 & & \\
\hline $50 \mathrm{~m}$ & $34.2 \%$ & 1 & & \\
\hline
\end{tabular}

in each arrangement of houses. The $h_{\mathrm{p}}$ values are $1.2 \mathrm{~m}$, $4.0 \mathrm{~m}$, and $7.0 \mathrm{~m}$ when $H$ is $10 \mathrm{~m}$, and $1.2 \mathrm{~m}, 3.0 \mathrm{~m}$, and $5.0 \mathrm{~m}$ when $H$ is $7 \mathrm{~m}$, and $1.2 \mathrm{~m}$ and $3.0 \mathrm{~m}$ when $H$ is $4 \mathrm{~m}$. Other conditions are almost the same as those of Experiment Ib. The experimental results are analyzed in the same manner as described in Sect. 2.1.4, and 1,128 values of $\Delta L_{\mathrm{B}}$ are obtained for each combination of $H$ and $h_{\mathrm{p}}$.

Figure 20 shows two examples of unit patterns from
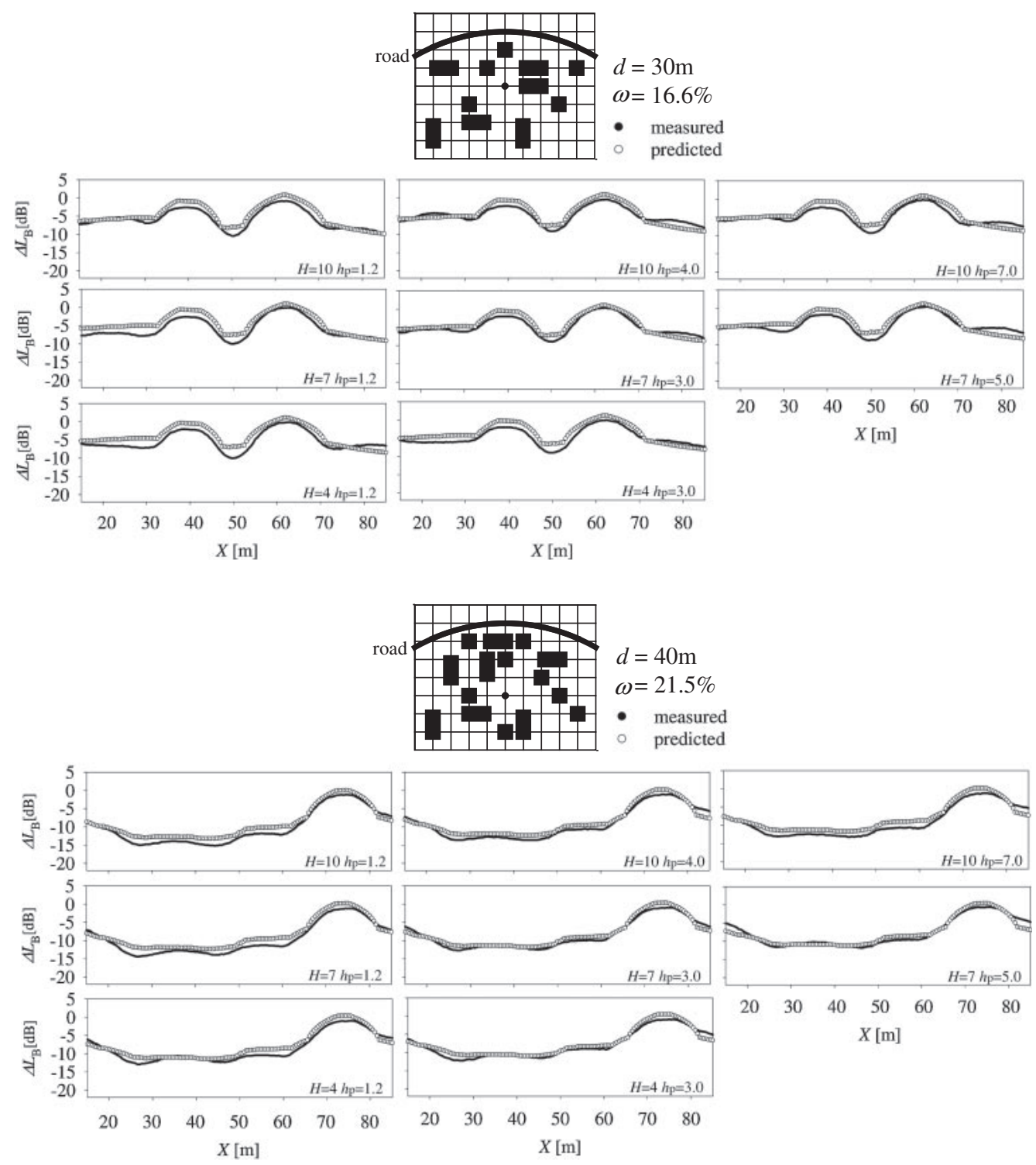

Fig. 20 Comparison of experimental unit patterns with predicted ones (Exp. IIa). 

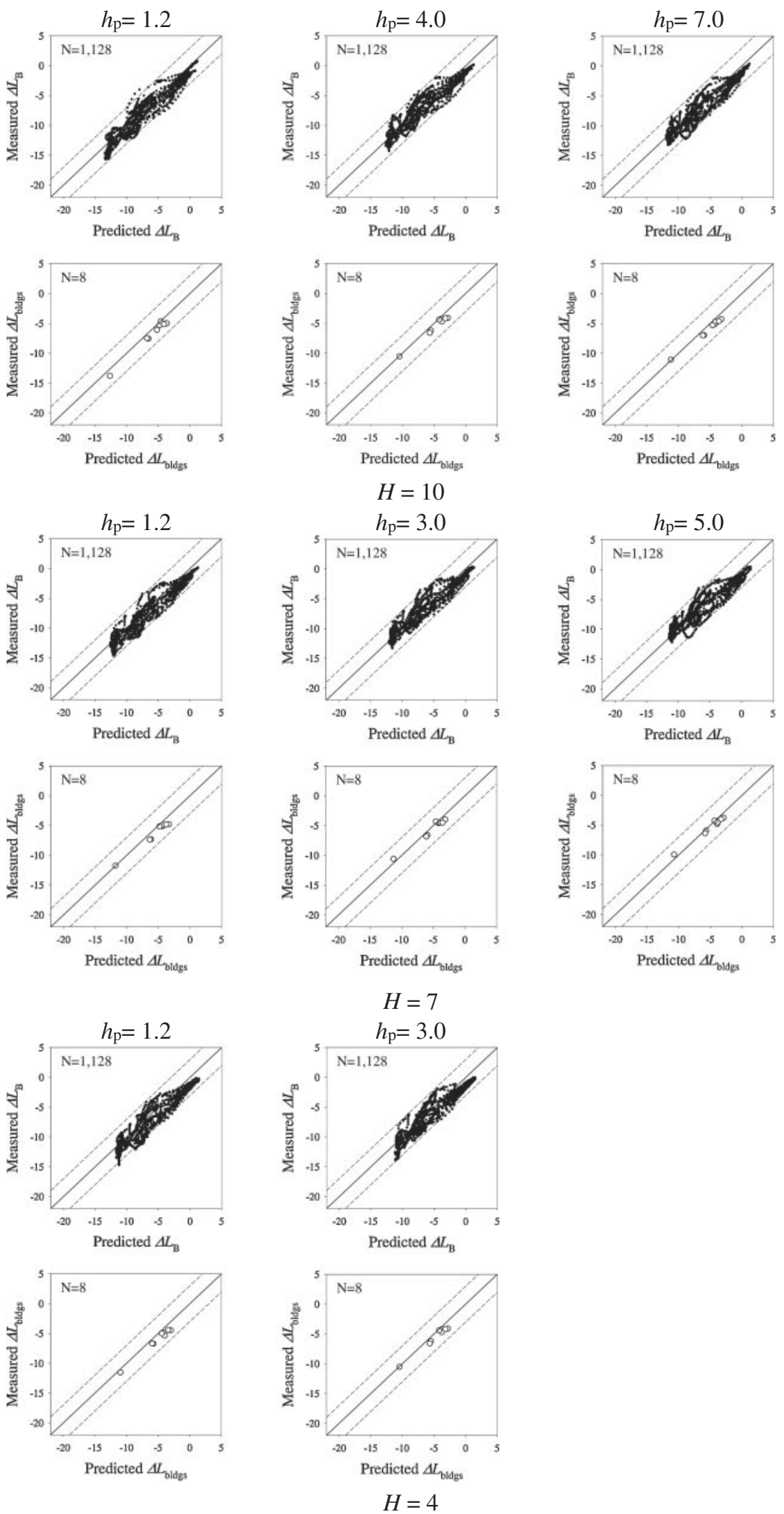

Fig. 21 Comparison of $\Delta L_{\mathrm{B}}$ and $\Delta L_{\text {bldgs }}$ with predicted ones (Exp. IIa).

among the 8 arrangements. Good agreement between experimental and predicted values is found. A comparison between the experimental and predicted $\Delta L_{\mathrm{B}}$ values is shown in Fig. 21. RMS and the maximum difference are $1.6 \mathrm{~dB}$ and $4.0 \mathrm{~dB}$, respectively. They are nearly equal to the values for a straight road $(1.9 \mathrm{~dB}$ and $6.4 \mathrm{~dB}$, respec- 
tively). Then, 8 values of $\Delta L_{\text {bldgs }}$ are compared with the calculated ones. RMS and the maximum difference are $1.0 \mathrm{~dB}$ and $1.4 \mathrm{~dB}$, respectively, and they are nearly equal to the values for a straight road $(0.8 \mathrm{~dB}$ and $1.9 \mathrm{~dB}$, respectively). The above results show that F2012 can predict the insertion loss of detached houses against road traffic noise for a curved road with almost the same accuracy as for a straight road.

\section{CONCLUSIONS}

One-twentieth-scale-model experiments were performed and a new formula for predicting the insertion loss of detached houses against road traffic noise using a point sound source model named F2012 was proposed. The validity and accuracy of F2012 were verified by additional experiments and comparison with the previous prediction formula using a line sound source model (F2006). Since F2012 can predict the insertion loss of detached houses against road traffic noise at any point lower than houses with a height of less than $10 \mathrm{~m}, \mathrm{~F} 2012$ is applicable to the evaluation of EQS in areas along not only a straight road but also a curved road.

\section{ACKNOWLEDGEMENTS}

This work was supported by JSPS KAKENHI Number 24560715. The authors wish to thank Ms. Tomoko Hirata for her help with experiments and analyses.

\section{REFERENCES}

[1] Environmental Quality Standards for Noise, Notification No. 64 of the Environmental Agency in Japan (1998).

[2] K. Fujimoto, K. Yamaguchi, T. Nakanishi and K. Anai, "Prediction of insertion loss of road traffic noise caused by detached houses in an area facing a plane road," J. Acoust. Soc.
Jpn. (J), 63, 309-317 (2007) (in Japanese).

[3] K. Yamaguchi, K. Fujimoto, K. Anai and Y. Hiraguri, "Prediction of insertion loss of road traffic noise caused by detached houses in an area facing an embanked road," J. INCE/ $J$, 33, 153-161 (2009) (in Japanese).

[4] K. Yamamoto, "Road traffic noise prediction model "ASJ RTNModel 2008": Report of the Research Committee of Road Traffic Noise," Acoust. Sci. \& Tech., 31, 2-48 (2010).

[5] K. Fujimoto, K. Tsuji and T. Tominaga, "Prediction of insertion loss of detached houses against road traffic noise based on a point sound source model," Tec. Rep. Noise Vib. Acoust. Soc. Jpn., N-2013-07 (2013) (in Japanese).

[6] T. Tominaga, K. Morita and K. Fujimoto, "Prediction of insertion loss of detached houses against road traffic noise based on a point sound source model- Prediction formula considering the heights of buildings and receiving point," Tec. Rep. Noise Vib. Acoust. Soc. Jpn., N-2014-09 (2014) (in Japanese).

Kazutoshi Fujimoto graduated from Kyushu University in 1972 and received Dr. Eng. degree from Kyushu University in $1986 . \mathrm{He}$ is currently a professor at Department of Architecture, Kyushu University in Japan. His research interests include a prediction and evaluation of road traffic noise and a development of soundabsorbing panel applying Helmholtz resonator. He is a member of ASJ, Architectural Institute of Japan and Institute of Noise Control Engineering of Japan.

Kyosuke Tsuji graduated from Graduate School of Kyushu University in 2013. He currently works at Daiwa Lease Co., Ltd. He has studied a part of this paper as his master thesis.

Toru Tominaga graduated from Graduate School of Kyushu University in 2014. He currently works at Kyushu Railway Company. He has studied a part of this paper as his master thesis.

Kengo Morita graduated from Kyushu University in 2013. He is currently a graduate student at Department of Architecture, Kyushu University and studies a prediction of the insertion loss of buildings against road traffic noise. He is a member of ASJ and Architectural Institute of Japan. 